\title{
PREDIKSI JUMLAH SISWA BARU YANG MENDAFTAR MENGGUNAKAN EKSPONENSIAL GANDA SATU-PARAMETER DARI BROWN
}

\author{
Aden $^{1, \text { a) }}$ dan Ahmad Labib Al Jauzi ${ }^{2, \text { b) }}$ \\ ${ }^{1,2}$ Program Studi Matematika, FMIPA - UNPAM \\ Email: ${ }^{\text {a) }}$ dosen00526@unpam.ac.id b)2014100078@unpam.ac.id
}

\begin{abstract}
ABSTRAK
Forcasting merupakan hal yang penting untuk mengetahui jumlah yang diperlukan dalam pengambilan keputusan waktu yang akan datang dalam sebuah penelitian. Tujuan penelitian yang dilaksanakan yaitu untuk mengetahui prediksi jumlah siswa SMPIT Darul Hikam menggunakan metode Ekspnensial Ganda Satu-Parameter dari Brown pada tahun 2018/2019, 2019/2020, dan 2020/2021 dan untuk mengetahui ketepatan metode Satu-Parameter dari Brown dalam memprediksikan jumlah siswa baru SMPIT Darul Hikam pada tahun 2018/2019, 2019/2020, dan 2020/2021. Metode penelitian menggunakan metode analisa Eksponensial Ganda Satu Parameter dari Brown. Kesimpulan dari penelitian yaitu prediksi jumlah siswa menggunakan metode Satu-Parameter dari Brown yang mendaftar di SMPIT Darul Hikam pada tahun ajaran 2018/2019 sebesar 38 siswa, tahun 2019/2020 sebesar 40 siswa, dan tahun 2020/2021 sebesar 41 siswa dan metode Satu-Parameter dari Brown adalah metode yang tepat, karena dengan $\alpha=0.2$, diperoleh $F_{t+m}$ (besarnya forecast) 38.89 dan rata-rata Gallat Absollute (MAE) 2.67.
\end{abstract}

Kata kunci: Eksponensial, Satu Parameter dari Brown, Gallat

\section{ABTRACT}

Forcasting is important to know the amount needed in making future decisions in a study. The aims of the research carried out is to determine the prediction of the number of students of Darul Hikam SMPIT using Brown's One-Parameter Double Expansion Method in 2018/2019, 2019/2020, and 2020/2021 and to determine the accuracy of Brown's One-Parameter method in predicting the number of students new Darul Hikam Middle School in 2018/2019, 2019/2020, and 2020/2021. The research method uses Brown's One Parameter Dual Exponential analysis method. The conclusion of the study is the prediction of the number of students using the OneParameter method from Brown who enrolled at SMPIT Darul Hikam in the 2018/2019 school year by 38 students, 2019/2020 by 40 students, and by 2020/2021 by 41 students and the One-Method The parameter of Brown is the right method, because with $\alpha=$ 0.2 , obtained $F_{-}(t+m)$ (forecast size) 38.89 and the average Gallat Absollute (MAE) 2.67 .

Keywords: Exponential, One Parameter from Brown, Gallat 


\section{PENDAHULUAN}

\subsection{Latar Belakang Masalah}

Pendidikan adalah usaha sadar dan terencana untuk mewujudkan suasana belajar dan proses pembelajaran agar peserta didik secara aktif mengembangkan potensi dirinya untuk memiliki kekuatan spiritual keagamaan, pengendalian diri, kepribadian, kecerdasan, akhlak mulia, serta keterampilan yang diperlukan dirinya, masyarakat, bangsa dan negara. Sehingga dalam melaksanakan prinsip penyelenggaraan pendidikan harus sesuai dengan tujuan pendidikan nasional yaitu mengembangkan kemampuan dan membentuk watak serta peradaban bangsa yang bermartabat dalam rangka mencerdaskan kehidupan bangsa, bertujuan untuk berkembangnya potensi peserta didik agar menjadi manusia yang beriman dan bertakwa kepada Tuhan Yang Maha Esa, berakhlak mulia, sehat, berilmu, cakap, kreatif, mandiri, dan menjadi warga negara yang demokratis serta bertanggung jawab.

Proses pendidikan digunakan evaluasi, akreditasi dan sertifikasi untuk memantau perkembangan pendidikan. Evaluasi dilakukan dalam rangka pengendalian mutu pendidikan secara nasional sebagai bentuk akuntabilitas penyelenggara pendidikan kepada pihak-pihak yang berkepentingan. Salah satu bentuk evaluasi pendidikan adalah dengan diadakannya ujian nasional baik di jenjang SD/MI, SMP/MTs dan SMA/MA. Ujian nasional memang tidak dapat dijadikan satu-satunya tolak ukur kualitas pendidikan disekolah tersebut akan tetapi ujian nasional merupakan indikator pertama dan paling terlihat di masyarakat untuk mengukur kualitas pendidikan.

Pembelajaran merupakan jantung dari proses pendidikan dalam suatu institusi pendidikan. Kualitas pembelajaran bersifat kompleks dan dinamis, dapat dipandang dari berbagai persepsi dan sudut pandang melintasi garis waktu. Pada tingkat mikro, pencapaian kualitas pembelajaran merupakan tanggungjawab profesional seorang guru, misalnya melalui penciptaan pengalaman belajar yang bermakna bagi siswa dan fasilitas yang didapat siswa untuk mencapai hasil belajar yang maksimal. Pada tingkat makro, melalui sistem pembelajaran yang berkualitas, lembaga pendidikan bertanggungjawab terhadap pembentukan tenaga pengajar yang berkualitas, yaitu yang dapat berkontribusi terhadap perkembangan intelektual, sikap, dan moral dari setiap individu peserta didik sebagai anggota masyarakat.

Faktor-faktor yang berpengaruh terhadap proses pembelajaran, baik secara eksternal maupun internal diidentifikasikan sebagai berikut. Faktor-faktor eksetrnal mencakup guru, materi, pola interaksi, media dan teknologi, situasi belajar dan sistem. Masih ada pendidik yang kurang menguasai materi dan dalam mengevaluasi siswa menuntut jawaban yang persis seperti yang ia jelaskan. Dengan kata lain siswa tidak diberi peluang untuk berfikir kreatif. Guru juga mempunyai keterbatasan dalam mengakses informasi baru yang memungkinkan ia mengetahui perkembangan terakhir dibidangnya (state of the art) dan kemungkinan perkembangan yang lebih jauh dari yang sudah dicapai sekarang (frontier of knowledge). Sementara itu materi 
pembelajaran dipandang oleh siswa terlalu teoritis, kurang memanfaatkan berbagai media secara optimal (Anggara, 2007:100).

Dengan semakin meningkatnya pertumbuhan masyarakat, semakin meningkat pula kebutuhan masyarakat terhadap pendidikan. Untuk memenuhi kebutuhan masyarakat tersebut, didirikanlah Sekolah Menengah Pertama Islam Terpadu Darul Hikam. Kemajuan suatu sekolah dipengaruhi oleh besar kecilnya kualitas kelulusan. Dilihat dari jumlah calon peserta didik baru di SMPIT Darul Hikam mempunyai skala peminat yang lumayan besar. Peramalan jumlah calon peserta didik baru tahun ajaran 2018/2019, 2019/2020, dan 2020/2021 merupakan salah satu hal yang sangat penting dalam pengambilan keputusan di SMPIT Darul Hikam tersebut. Bagi pihak sekolah peramalan ini berfungsi untuk menentukan prioritas serta berapa jumlah calon peserta didik yang akan diterima. Maka dari itu perlu dilakukan prediksi yang tepat (Aden: 2018).

Dalam uraian di atas tampak jelas bahwa peramalan jumlah calon peserta didik baru sangat dibutuhkan oleh pejabat pelaksana teknis kegiatan (PPTK) yaitu kepala sekolah pada tahun 2018/2019, 2019/2020, dan 2020/2021 mendatang di SMPIT Darul Hikam.

\subsection{Perumusan Masalah}

Setelah mengemukakan latar belakang masalah, identifikasi masalah, dan pembatasan masalah, maka peneliti mencoba merumuskan masalah ke dalam bentuk pertanyaan sebagai berikut:

1. Bagaimana memprediksikan jumlah siswa SMPIT Darul Hikam dengan menggunakan metode Satu-Parameter dari Brown pada tahun 2018/2019, 2019/2020, dan 2020/2021?

2. Apakah metode Satu-Parameter dari Brown ini cukup tepat dalam memprediksikan jumlah siswa SMPIT Darul Hikam pada tahun 2018/2019, 2019/2020, dan 2020/2021?

\subsection{Tujuan Penelitian}

Berdasarkan rumusan masalah di atas maka tujuan penelitian ini adalah sebagai berikut :

1. Untuk mengetahui prediksi jumlah siswa SMPIT Darul Hikam menggunakan metode Satu-Parameter dari Brown pada tahun 2018/2019, 2019/2020, dan 2020/2021.

2. Untuk mengetahui ketepatan metode Satu-Parameter dari Brown dalam memprediksikan jumlah siswa baru SMPIT Darul Hikam pada tahun 2018/2019, 2019/2020, dan 2020/2021.

\section{METODE PENELITIAN}

\subsection{Metodologi}

Metode penelitian yang dilaksanakan menggunakan metode penelitian survei. Menurut Sugiyono (2016: 8) metode merupakan Metode penelitian merupakan suatu penyelidikan yang sistematis untuk meningkatkan sejumlah pengtahuan, juga 
merupakan suatu usaha yang sistematis dan terorganisasi untuk menyelidiki masalah tertentu yang memerlukan jawaban. Metode penelitian kuantitatif dapat diartikan sebagai metode penelitian yang berlandaskan pada pilsafat positivisme, digunakan untuk meneliti pada populasi dan sampel tertentu, pengumpulan data menggunakan instrumen penelitian, analisis data bersifat kuantitatif atau statistik, dengan tujuan untuk menguji hipotesis yang telah ditetapkan.

\subsection{Populasi dan Sampel}

a. Sampel

Sample penelitian ini adalah data Jumlah siswa SMPIT Darul Hikam dari tahun ajaran 2010/2011 - 2017/2018.

b. Cara Pengimputan Data

Dalam Penelitian ini digunaan metode-metode sebagai berikut :

1) Teknik Studi Kepustakaan

Studi kepustakaan ini dilakukan dengan mengumpulkan dan menganalisis beberapa sumber bacaan yang berkaitan dengan masalah yang diteliti.

2) Metode Dokumentasi

Metode dokumentasi ini digunakan dalam mencari data-data yang terkait dengan judul penelitian.

\subsection{Metode Analisis Data}

Untuk menganalisis data penelitian ini, peneliti menggunakan metode Pemulusan Eksponensial Ganda Satu-Parameter dari Brown. Adapun tahapan dari metode ini adalah sebagai berikut :

Prosedur analisis adalah (1) Membuat plot data deret waktu; (2) Melakukan inisialisasi nilai awal (3) Melakukan pemodelan Metode Brown (4) Menentukan nilai konstanta pemulusan (5) Melihat kelayakan model dengan membuat plot ACF dari sisaan; (6) Melakukan peramalan dengan Metode Brown; (7) Melakukan inisialisasi nilai awal pada Sistem Pemantauan; (8) Melakukan pemodelan dari Sistem Pemantaua; (9) Langkah terakhir adalah membandingkan ukuran ketepatan dari Metode Brown dan Holt dan membandingkan dari segi kesalahan sistematis dengan menggunakan Sistem Pemantauan.

\section{HASIL DAN PEMBAHASAN}

\subsection{Hasil Penelitian}

Data yang digunakan adalah data jumlah siswa baru SMPIT Darul Hikam dari tahun ajaran 2010/2011 - 2017/2018. Adapun tabel yang disajikan adalah sebagai berikut : 
Tabel 4.1 Perkembangan jumlah siswa baru SMPIT Darul Hikam.

\begin{tabular}{|c|c|c|}
\hline No & Tahun Ajaran & Jumlah Siswa \\
\hline 1 & $2006 / 2007$ & 10 \\
\hline 2 & $2007 / 2008$ & 19 \\
\hline 3 & $2008 / 2009$ & 7 \\
\hline 4 & $2009 / 2010$ & 24 \\
\hline 5 & $2010 / 2011$ & 60 \\
\hline 6 & $2011 / 2012$ & 27 \\
\hline 7 & $2012 / 2013$ & 35 \\
\hline 8 & $2013 / 2014$ & 42 \\
\hline 9 & $2014 / 2015$ & 36 \\
\hline 10 & $2015 / 2016$ & 43 \\
\hline 11 & $2016 / 2017$ & 36 \\
\hline 12 & $2017 / 2018$ & 28 \\
\hline
\end{tabular}

Berdasarkan tabel diatas dibuat grafik seperti terlihat pada gambar 4.1

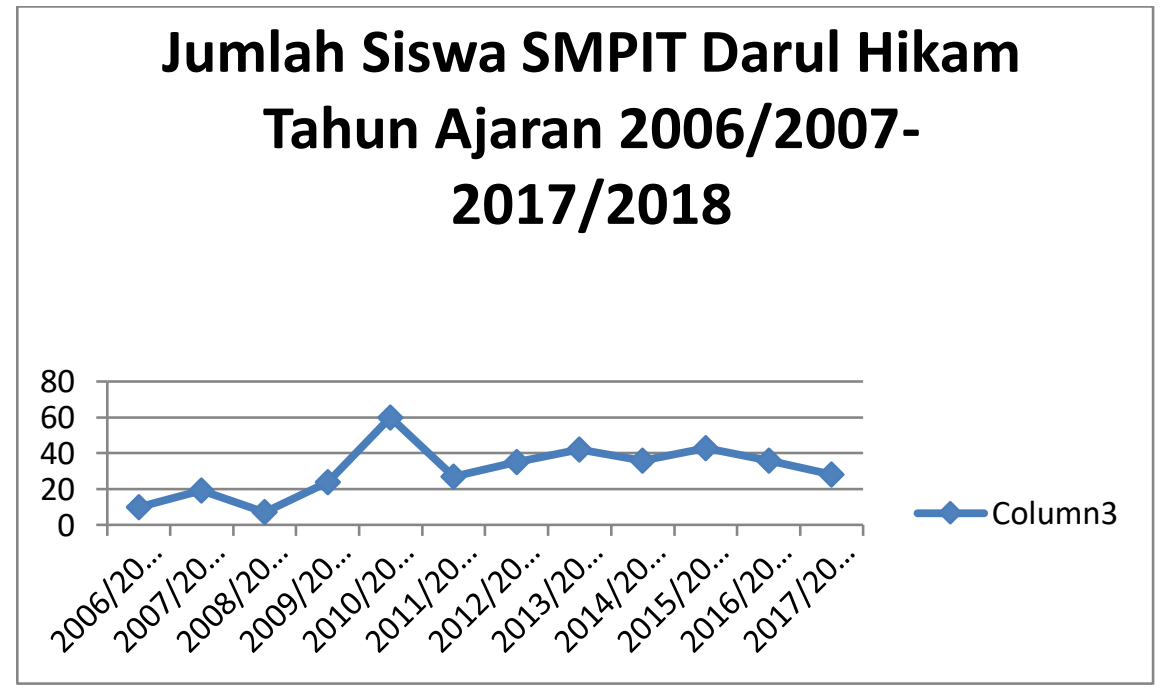

Gambar 4.1

\section{Jumlah Siswa SMPIT Darul Hikam Tahun Ajaran 2006/2007-2017/2018}

\subsection{Analisis Data}

Berikut ini adalah tabel perhitungan data yang diperoleh dengan metode Pemulusan Eksponensial Ganda Satu-Parameter dari Brown

1. Perhitungan $S ' t$

$$
\begin{aligned}
& \mathrm{S}^{\prime}{ }_{1}=\mathrm{X}_{1}=10,00 \\
& \mathrm{~S}_{2}=\alpha \mathrm{X}_{2}+(1-\alpha) \mathrm{S}{ }_{1}=0.2(19)+(1-0.2)(10.00)=11.80
\end{aligned}
$$


$\mathrm{S}_{3}{ }_{3}=\alpha \mathrm{X}_{3}+(1-\alpha) \mathrm{S}_{2}=0.2(7)+(1-0.2)(11.80)=10.84$

Dan seterusnya samapi dengan ke-12

2. Perhitungan $S$ ''t

$\mathrm{S}_{1}{ }_{1}=\mathrm{X}_{1}=10,00$

$\mathrm{S}{ }_{2}=\alpha \mathrm{S}{ }_{2+}+(1-\alpha) \mathrm{S}{ }_{1}=0.2(11.80)+(1-0.2)(10.00)=10.36$

$\mathrm{S}_{3}=\alpha \mathrm{S}_{3}+(1-\alpha) \mathrm{S}{ }_{2}=0.2(10.84)+(1-0.2)(10.36=10.46$

Dan seterusnya samapi dengan ke-12

3. Perhitungan at

$$
\begin{aligned}
& \mathrm{a}_{1}=2 \mathrm{~S}^{\prime}{ }_{1}-\mathrm{S}{ }_{1}=2(10.00)-(10.00)=10.00 \\
& \mathrm{a}_{2}=2 \mathrm{~S}_{2}-\mathrm{S}_{2}{ }_{2}=2(11.80)-(10.36)=13.24 \\
& \mathrm{a}_{3}=2 \mathrm{~S}_{3}-\mathrm{S}{ }_{3}=2(10.84)-(10.46)=11.32
\end{aligned}
$$

Dan seterusnya samapi dengan ke-12

4. Perhitungan bt

$\mathrm{b}_{1}=\frac{\alpha}{(1-\alpha)}\left(\mathrm{S}^{\prime}{ }_{1}-\mathrm{S}^{\prime}{ }_{1}\right)=\frac{0.2}{(1-0.2)}(10.00-10.00)=0.00$

$\mathrm{b}_{2}=\frac{\alpha}{(1-\alpha)}\left(\mathrm{S}_{2}-\mathrm{S}_{2}{ }_{2}\right)=\frac{0.2}{(1-0.2)}(11.80-10.36)=0.36$

$\mathrm{b}_{3}=\frac{\alpha}{(1-\alpha)}\left(\mathrm{S}_{3}{ }_{3}-\mathrm{S}_{3}{ }_{3}\right)=\frac{0.2}{(1-0.2)}(10.84-10.46)=0.10$

Dan seterusnya samapi dengan ke-12

5. Perhitungan $\mathrm{F}$

$$
\begin{aligned}
& F_{1+1}=a_{1}+b_{1} m=10.00+(0.00 \times 1)=10.00 \\
& F_{2+1}=a_{2}+b_{2} m=13.24+(0.36 \times 1)=13.60 \\
& F_{3+1}=a_{3}+b_{3} m=11.22+(0.10 \times 1)=11.32 \\
& F_{13+1}=a_{13}+b_{13} m=37.61+(1.28 \times 2)=40.11
\end{aligned}
$$

Dan seterusnya samapi dengan ke-12

\subsection{Tabel Perhitungan}

Tabel 4.2 Hasil perhitungan jumlah siswa dengan menggunakan metode Pemulusan Eksponensial Ganda Satu-Parameter dari Brown

\begin{tabular}{|c|c|c|c|c|c|c|}
\hline Periode & $\mathrm{Xt}$ & $\mathrm{S} ' \mathrm{t}$ & $\mathrm{S} " \mathrm{t}$ & at & bt & $\mathrm{Ft}$ \\
\hline 1 & 10,00 & 10,00 & 10,00 & 10,00 & 0,00 & \\
\hline 2 & 19,00 & 11,80 & 10,36 & 13,24 & 0,36 & 10,00 \\
\hline 3 & 7,00 & 10,84 & 10,46 & 11,22 & 0,10 & 13,60 \\
\hline 4 & 24,00 & 13,47 & 11,06 & 15,88 & 0,60 & 11,32 \\
\hline 5 & 60,00 & 22,78 & 13,40 & 32,15 & 2,34 & 16,49 \\
\hline 6 & 27,00 & 23,62 & 15,45 & 31,80 & 2,04 & 34,50 \\
\hline 7 & 35,00 & 25,90 & 17,54 & 34,26 & 2,09 & 33,84 \\
\hline 8 & 42,00 & 29,12 & 19,85 & 38,38 & 2,32 & 36,35 \\
\hline 9 & 36,00 & 30,49 & 21,98 & 39,01 & 2,13 & 40,70 \\
\hline
\end{tabular}




\begin{tabular}{|c|c|c|c|c|c|c|}
\hline Periode & $\mathrm{Xt}$ & $\mathrm{S} ' \mathrm{t}$ & $\mathrm{S} " \mathrm{t}$ & at & $\mathrm{bt}$ & $\mathrm{Ft}$ \\
\hline 10 & 43,00 & 33,00 & 24,18 & 41,81 & 2,20 & 41,14 \\
\hline 11 & 36,00 & 33,60 & 26,07 & 41,13 & 1,88 & 44,01 \\
\hline 12 & 28,00 & 32,48 & 27,35 & 37,61 & 1,28 & 43,01 \\
\hline 13 & & & & & 38,89 \\
\hline 14 & & & & & & 40,17 \\
\hline 15 & & & & & & 41,45 \\
\hline
\end{tabular}

\subsection{Analisis Gallat}

\subsubsection{Gallat}

Perhitungan galat Hotel Bintang dari Brown :

1. Galat $\left(e_{i}\right)$

$$
\begin{aligned}
& e_{i}=X_{i}-F_{i} \\
& e_{1}=- \\
& e_{2}=19.00-10.00=9.00
\end{aligned}
$$

dan seterusnya sehingga diperoleh

$$
\sum e_{i}=32.04
$$

2. Rata - rata Galat (ME)

$$
\mathrm{ME}=\frac{\sum_{i=1}^{n} e i}{n}=\frac{(32.04)}{12}=2.67
$$

3) Nilai Tengah Galat Absolut (MAE)

$$
\mathrm{MAE}=\frac{\sum_{i=1}^{n}|e i|}{n}=\frac{(32.04)}{12}=2.67
$$

4) Jumlah Kuadrat Galat (SSE)

$$
\mathrm{SSE}=\sum_{i=1}^{n} e^{2} i=2582.99
$$

5) Nilai Tengah Galat Kuadrat (MSE)

$$
\text { MSE }=\frac{\sum_{i=1}^{n} e^{2} i}{n}=\frac{2582.99}{12}=215.25
$$

6) Deviasi Standar Galat (SDE)

$$
\mathrm{SDE}=\sqrt{\frac{\sum_{i=1}^{n} e^{2} i}{n}}=\sqrt{\frac{2582.99}{12}}=15.32
$$

7) Galat Persentase (PE)

$$
\begin{aligned}
& \mathrm{PE}_{\mathrm{t}}=\frac{X t-F t}{X t}(100) \\
& \mathrm{PE}_{1}=\text { - } \\
& \mathrm{PE}_{2}=\frac{X 2-F 2}{X 2}(100)=\frac{19.00-10.00}{19.00}(100) \quad=47.37 \\
& \mathrm{PE}_{3}=\frac{X 3-F 3}{X 3}(100)=\frac{7.00-13.60}{7.00}(100) \quad=-94.29
\end{aligned}
$$




$$
\mathrm{PE}_{4}=\frac{X 4-F 4}{X 4}(100)=\frac{24.00-13.32}{24.00}(100)=52.83
$$

Dan seterusnya sampai dengan ke-12, sehingga

$$
\sum \mathrm{PE}=-17.17
$$

8) Nilai Tengah Galat Persentase (MPE)

$$
\mathrm{MPE}=\frac{\sum_{i=1}^{n} P E i}{n}=\frac{(-17.17)}{12}=-1.43
$$

9) Nilai Tengah Galat Persentase Absolut (MAPE)

$$
\text { MAPE }=\frac{\sum_{i=1}^{n}|P E i|}{n}=\frac{17.17}{12}=1.43
$$

10) Naif 1

$$
\begin{aligned}
& N F_{1}=- \\
& N F_{2}=\frac{\sum_{i=1}^{n}\left|\frac{x_{i}-x_{i}-1}{x_{i}}\right|}{n-1}=\frac{\left|\frac{19.00-10.00}{19.00}\right|}{12-1} 100=2.06 \\
& N F_{3}=\frac{\sum_{i=1}^{n}\left|\frac{x_{i}-x_{i}-1}{x_{i}}\right|}{n-1}=\frac{\left|\frac{7.00-13.60}{7.00}\right|}{12-1} 100=7.45
\end{aligned}
$$

Sampai dengan ke-12 sehingga

$$
\sum \mathrm{NF}=25.75
$$

11. Ramalan Naif 1 (NF1)

$$
\mathrm{NF} 1=\frac{\sum_{i=2}^{n}\left|\frac{X_{i}-X_{i-1}}{X i}\right|}{n-1}(100)=\frac{25.75}{12-1}(100)=234.09
$$

\subsubsection{Tabel Pengamatan Gallat}

Tabel 4.3 Hasil perhitungan gallat

\begin{tabular}{|c|c|c|c|c|c|c|c|}
\hline Periode & $\boldsymbol{X}_{\boldsymbol{t}}$ & $\boldsymbol{F}_{\boldsymbol{t}}$ & $\boldsymbol{e}_{\boldsymbol{i}}$ & $\boldsymbol{e}_{\boldsymbol{i}^{\mathbf{2}}}$ & $\mathbf{P E}$ & $|\mathbf{P E}|$ & $\mathbf{N F 1}$ \\
\hline 1 & 10,00 & & & & & & \\
\hline 2 & 19,00 & 10,00 & 9,00 & 9,00 & 47,37 & 47,37 & 2,06 \\
\hline 3 & 7,00 & 13,60 & $-6,60$ & 6,60 & $-94,29$ & 94,29 & 7,45 \\
\hline 4 & 24,00 & 11,32 & 12,68 & 12,68 & 52,83 & 52,83 & 3,08 \\
\hline 5 & 60,00 & 16,49 & 43,51 & 43,51 & 72,52 & 72,52 & 2,61 \\
\hline 6 & 27,00 & 34,50 & $-7,50$ & 7,50 & $-27,78$ & 27,78 & 5,31 \\
\hline 7 & 35,00 & 33,84 & 1,16 & 1,16 & 3,31 & 3,31 & 0,99 \\
\hline 8 & 42,00 & 36,35 & 5,65 & 5,65 & 13,45 & 13,45 & 0,72 \\
\hline 9 & 36,00 & 40,70 & $-4,70$ & 4,70 & $-13,06$ & 13,06 & 0,72 \\
\hline 10 & 43,00 & 41,14 & 1,86 & 1,86 & 4,33 & 4,33 & 0,71 \\
\hline 11 & 36,00 & 44,01 & $-8,01$ & 8,01 & $-22,25$ & 22,25 & 0,85 \\
\hline 12 & 28,00 & 43,01 & $-15,01$ & 15,01 & $-53,61$ & 53,61 & 1,24 \\
\hline & & 38,89 & & & & & \\
\hline
\end{tabular}




\begin{tabular}{|c|c|c|c|c|c|c|c|}
\hline \multirow[t]{3}{*}{ Periode } & $X_{t}$ & $F_{t}$ & $e_{i}$ & $e_{i^{2}}$ & $\mathbf{P E}$ & $|\mathbf{P E}|$ & NF1 \\
\hline & & 40,17 & & & & & \\
\hline & & 41,45 & & & & & \\
\hline$\sum$ & 367,00 & 445,47 & 32,04 & 115,68 & $-17,17$ & 404,79 & 25,75 \\
\hline
\end{tabular}

\subsubsection{Statistik $U$ dari Theil}

Statistik-U dari Theil (U)

$$
\mathrm{U}=\sqrt{\frac{\sum_{i=1}^{n-1}\left(\frac{F_{i+1}-X_{i+1}}{X_{i}}\right)^{2}}{\sum_{i=1}^{n-1}\left(\frac{X_{i+1}-X_{i}}{X_{i}}\right)^{2}}} \sqrt{\frac{1.01}{1.05}}=0.98
$$

\subsubsection{Statistik Durbin Watson (D-W)}

Tabel 4.4 Statistik Durbin Watson (D-W)

\begin{tabular}{|c|c|c|c|r|r|}
\hline Periode & $\boldsymbol{X}_{\boldsymbol{t}}$ & \multicolumn{1}{c|}{$\boldsymbol{F}_{\boldsymbol{t}}$} & \multicolumn{1}{c|}{$\boldsymbol{e}_{\boldsymbol{i}}$} & \multicolumn{1}{c|}{ D-W pem } & \multicolumn{1}{l|}{ D-W pen } \\
\hline 1 & 10,00 & & & & \\
\hline 2 & 19,00 & 10,00 & 9,00 & & 81,00 \\
\hline 3 & 7,00 & 13,60 & $-6,60$ & 243,36 & 43,56 \\
\hline 4 & 24,00 & 11,32 & 12,68 & 371,72 & 160,78 \\
\hline 5 & 60,00 & 16,49 & 43,51 & 950,49 & 1893,12 \\
\hline 6 & 27,00 & 34,50 & $-7,50$ & 2602,02 & 56,25 \\
\hline 7 & 35,00 & 33,84 & 1,16 & 75,00 & 1,35 \\
\hline 8 & 42,00 & 36,35 & 5,65 & 20,16 & 31,92 \\
\hline 9 & 36,00 & 40,70 & $-4,70$ & 107,12 & 22,09 \\
\hline 10 & 43,00 & 41,14 & 1,86 & 43,03 & 3,46 \\
\hline 11 & 36,00 & 44,01 & $-8,01$ & 97,42 & 64,16 \\
\hline 12 & 28,00 & 43,01 & $-15,01$ & 49,00 & 225,30 \\
\hline & & 38,89 & & & \\
\hline & & 40,17 & & & \\
\hline$\sum$ & 367,00 & 445,47 & 32,04 & 4559,32 & 2582,99 \\
\hline
\end{tabular}




$$
\mathrm{D}-\mathrm{W}=\frac{\sum_{t=2}^{n}\left(e_{t}-e_{t-1}\right)^{2}}{\sum_{t=1}^{n} e_{t}^{2}}=\frac{4559.32}{2582.99}=1.76
$$

\section{KESIMPULAN}

Dari hasil perhitungan dan analisis yang dilakukan mengenai jumlah siswa SMPIT Darul Hikam pada tahun 2017 menggunakan metode Pemulusan Eksponensial Ganda dengan $\alpha=0.2$ dan $\gamma=0.3$, maka peneliti dapat menyimpulkan bahwa :

1. Prediksi jumlah siswa menggunakan metode Satu-Parameter dari Brown yang mendaftar di SMPIT Darul Hikam pada tahun ajaran 2018/2019 sebesar 38 siswa, tahun 2019/2020 sebesar 40 siswa, dan tahun 2020/2021 sebesar 41 siswa.

2. Metode Satu-Parameter dari Brown adalah metode yang tepat, karena dengan $\alpha=$ 0.2, diperoleh $F_{t+m}$ (besarnya forecast) 38.89 dan rata-rata Gallat Absollute (MAE) 2.67.

\section{DAFTAR PUSTAKA}

Aden, A. (2018). ANALISIS KOMPARASI ESTIMASI JUMLAH PENJUALAN PRODUK DENGAN METODE EKSPONENSIAL TUNGGAL PENDEKATAN ADAPTIF DAN METODE EKSPONENSIAL GANDA DUA PARAMETER DARI HOLT.JURNAL SAINTIKA UNPAM (Jurnal Sains dan Matematika Unpam), 1(1), 1-19.

Arsyad, Lincolin.1994, Peramalan Bisnis, Edisi Pertama, BPFE, Yogyakarta.

Hyndman, R., A. B. Koehler, J. Keith Ord \& R. D. Snyder. 2008. Forecasting with exponential smoothing, Dalam : Salamena, Gerry Gilliant., 2011, Pengujian Model Peramalan Deret Waktu Sea Surface Temperature (SST) Teluk Ambon Luar dengan Metode Exponential Smoothing. UPT. Balai Konversi Biota Laut LIPI.

Kalekar, P. 2004. Time series forecasting using Holt-Winters exponential smoothing. Proceeding IT694 Seminar. Kanwal Rekhi School of Information Technology, 6 Desember 2004, Bombay : 1 - 13.

Leabo, D. A. \& C. F. Smith 1968. Basic statistics, Third Edition. Richard D., Darwin Inc. Illinois.

Spyros Makridakis, Steven C Wheelwright, dan Victor E McGee., "Metode dan Aplikasi Peramalan", Jilid 1, Banirupa Aksara, Tangerang, 1993. 


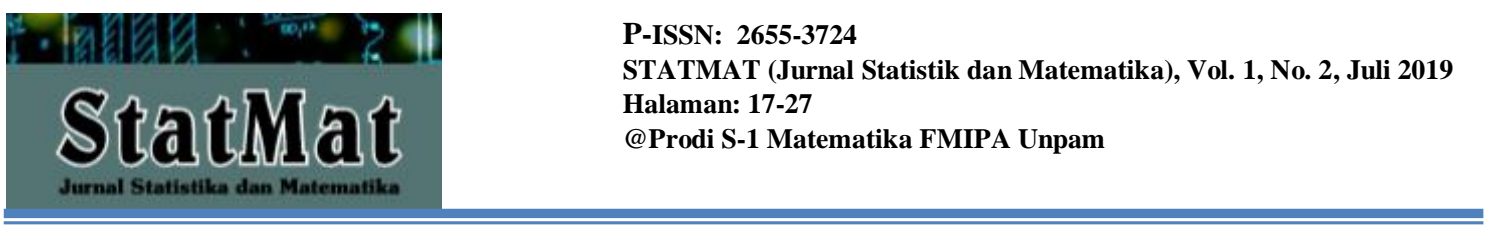

Xiaochen, Li., 2012, Comparion and Analysis between Holt Exponential Smoothing and Brown Exponential Smoothing Used for Freight Turnover Forecasts. Wuhan University of Technology : IEEE. 